\title{
Michael Thelwall wins the 2015 Derek John de Solla Price Medal
}

\author{
Kayvan Kousha $^{1} \cdot$ Jonathan Levitt $^{1}$
}

Received: 10 July 2015/Published online: 6 August 2015

(c) Akadémiai Kiadó, Budapest, Hungary 2015

The Editorial Board and the Publishers of Scientometrics are glad to announce that the 2015 Derek John de Solla Price Medal has been awarded to Michael Thelwall for his distinguished contribution to the field of sciento-metrics.

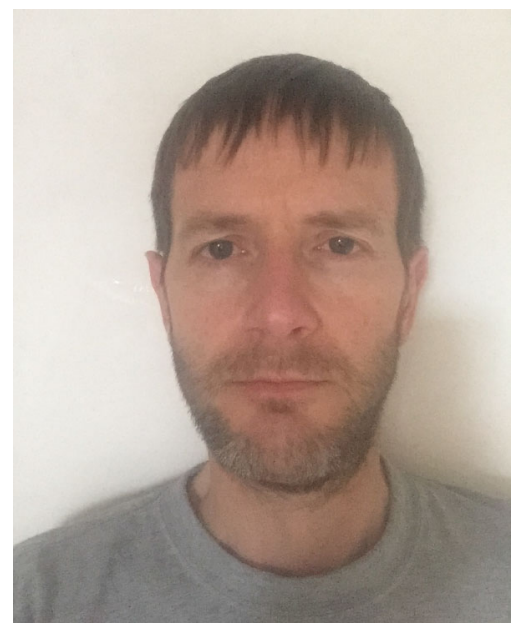

Michael Thelwall, the winner of the 2015 Derek John de Solla Price Medal

Kayvan Kousha

k.kousha@wlv.ac.uk

1 Statistical Cybermetrics Research Group, School of Technology, University of Wolverhampton, Wulfruna Street, Wolverhampton WV1 1LY, UK 


\section{Awardees of the Derek John de Solla Price Medal (1984-2015)}

1984 Eugene Garfield (USA)

1985 Michael J. Moravcsik (USA)

1986 Tibor Braun (Hungary)

1987 Vasiliy V. Nalimov (USSR) and Henry Small (USA)

1988 Francis Narin (USA)

1989 Bertram C. Brookes (England) and Jan Vlachý (Czechoslovakia)

1993 András Schubert (Hungary)

1995 Anthony F. J. van Raan (The Netherlands) and Robert K. Merton (USA)

1997 John Irvine and Ben Martin (England) and Belver C. Griffith (USA)

1999 Wolfgang Glänzel (Germany/Hungary) and Henk F. Moed (The Netherlands)

2001 Leo Egghe (Belgium) and Ronald Rousseau (Belgium)

2003 Loet Leydesdorff (The Netherlands)

2005 Peter Ingwersen (Denmark) and Howard D. White (USA)

2007 Katherine W. McCain (USA)

2009 Péter Vinkler (Hungary) and Michel Zitt (France)

2011 Olle Persson (Sweden)

2013 Blaise Cronin (USA)

2015 Michael Thelwall (UK)
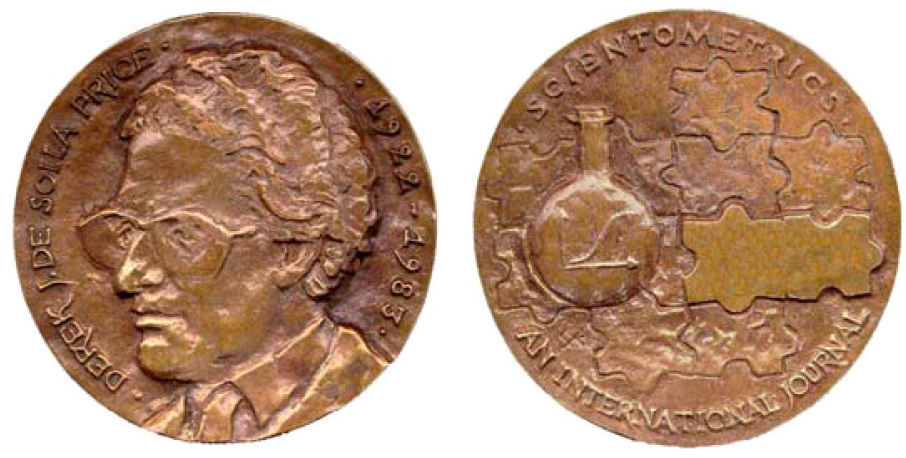

\section{Mike Thelwall-Recipient of the 2015 Derek John de Solla Price Medal}

\section{Kayvan Kousha and Jonathan Levitt}

Statistical Cybermetrics Research Group, School of Technology, University of Wolverhampton Wulfruna Street, Wolverhampton, WV1 1LY, UK

Mike Thelwall is Professor of Information Science at the University of Wolverhampton, Research Associate at the Oxford Internet Institute, and Docent at the Department of Information Studies at Åbo Akademi University in Finland. Mike obtained his PhD in Pure Mathematics from Lancaster University in 1989. He leads the Statistical Cybermetrics Research Group, which investigates the development of new methods and software for quantitative analysis of web objects. Mike has investigated the systematic ways in which a wide range of web indicators can be gathered to reflect types of impact that are different from that of traditional citations. 


\section{Statistical cybermetrics research group}

Mike Thelwall founded the Statistical Cybermetrics Research Group at the University of Wolverhampton in 2000; prior to then there had been no library and information science research at the university. In the UK's 2008 Research Assessment Exercise, the group was awarded jointly the second highest average score in Library and Information Management and three quarters of the group's submissions in the field of webometrics and scientometrics were rated as 'World leading'. In the UK's 2014 Research Excellence Framework (the REF) the Statistical Cybermetrics Research Group received an average score of 3.37 out of 4 with almost all of published research rated as 'world leading' or 'internationally excellent'; this score was higher than the institution-wide average score of every British university. Since its foundation, the group has been awarded close to $£ 1.5$ million in research funding, from diverse funding agencies including the European Union and the United Nations. In 2015 the Statistical Cybermetrics Research Group won the University of Wolverhampton's Award for Excellence in Research.

\section{Research contribution}

Mike's research contribution has been mainly in the development of theories and methods for extracting and analysing web data from an information science perspective. Mike has investigated many emerging areas and has addressed research problems in link analysis, citation analysis, altmetric analysis, and sentiment analysis. He has also contributed to quantitative methods in scientometrics and bibliometrics. Mike's scientific achievements have been disseminated in his three books, over 200 peerreviewed journal articles and numerous conference presentations. Mike has published over 100 articles in the Journal of the Association for Information Science and Technology, Scientometrics and the Journal of Informetrics. Mike has been a highly collaborative scientist; over 140 co-authors from 17 countries have co-authored articles with Mike.

Mike published his first article in the field, "Web Impact Factors and search engine coverage", about 15 years ago in 2000 and critically discussed the problems of using commercial search engines for web impact calculations. In recognition of this, he published a follow-up paper in 2001 and reported results from web crawler which he designed for the calculation of web impact factors. Remarkably, within 2 years during 2002 and 2003 he published over 30 articles (web of science), exploring aspects of Web hyperlinks and other web objects for scholarly communication research. In 2004, he published his first book 'Link analysis: An information science approach'. The book discusses theories, methods, case studies and limitations of using web link data for information science and social science research. In 2009, he wrote his second book, "Introduction to webometrics: Quantitative web research for the social sciences" and discussed web-based methods for measuring aspects of the web including blogs, social networks and online news for social scientists. From 2011 Mike and his colleagues mainly explored the metrics of social impact from a range of social web sites such as Twitter, MySpace, YouTube and TED videos, research blogs, f1000, Mendeley, Academia.edu, ResearchGate, Amazon.com and online syllabi. In 2014 Mike and his colleagues published over 20 articles in leading journals of the field, investigating the use of web artefacts for research assessment. 


\section{Editorial and reviewing}

Mike serves as an associate editor of Journal of the Association for Information Science and Technology and on the editorial boards of seven journals, including the Journal of Informetrics and Scientometrics. He has reviewed over 700 articles for academic journals in the profession.

\section{Software development}

Mike's research contribution is not limited to scientific publications. He has designed and developed four free computer applications: Webometric Analyst which is an altmetrics, web citation and webometrics data collector and analyser, SocSciBot which is a web crawler and hyperlink analyser, Mozdeh which is a Twitter time series analyst, and SentiStrength which is sentiment strength detection software. His tools help researchers and students to collect and analyse data from a range of web sources, such as the Bing search engine, YouTube, Twitter, the Mendeley reference manager, Google Books, Online Syllabi, Academia, ResearchGate and Worldcat. Mike's SentiStrength software automatically analyses negative or positive sentiments of up to 16,000 social web texts per second with human level accuracy for English and several other languages and is sold commercially; it is used by Yahoo! for its question answering service and is used to analyse the sentiment in tweets from the public for light shows, including on the London Eye throughout the London Olympics.

\section{Teaching and mentoring}

Mike's contribution to the field of webometrics and scientometrics is not restricted to the research. He has designed undergraduate and postgraduate cybermetrics courses at the University of Wolverhampton; the course is unique in that it combines mathematics, computing and information science with practical webometric techniques to collect and analyse web objects. Mike has given talks for PhD courses and summer schools in China, Russia, Germany, Spain and the USA. Mike has mentored seven post-doctoral fellows and over ten visiting scholars. Sixteen of Mike's research students have been awarded $\mathrm{PhD}$ degrees in the field of webometrics and scientometrics, two have won the Eugene Garfield Doctoral Dissertation Fellowship Award, and two have won prizes in the Student Paper Contest of ASIS\&T's Metrics Special Interest Group

We have benefitted greatly from work with Mike over the last 10 years and we know that many researchers and students have enjoyed very much working with him. Mike is more than an outstanding scientist: he is a generous, helpful and supportive colleague for many of us. Professor Mike Thelwall is a very worthy recipient of the Derek John de Solla Price Medal. 